\title{
Hepatoprotective effect of essential phospholipids enriched with virgin coconut oil (Phoscoliv) on paracetamol-induced liver toxicity
}

\author{
Sheethal Sreevallabhan ${ }^{1}$ | Ratheesh Mohanan ${ }^{1}$ (D) | Svenia P. Jose ${ }^{1}$ | \\ Sandya Sukumaran ${ }^{2}$ | Tariq Jagmag ${ }^{3}$ | Jayesh Tilwani ${ }^{3}$ | Anuradha Kulkarni ${ }^{3}$
}

${ }^{1}$ Department of Biochemistry, St. Thomas College, Palai, Kottayam, India

${ }^{2}$ Inorganic and Physical Chemistry, Indian Institute of Science, Bangalore, India

${ }^{3}$ Glowderma Pvt. Ltd, Mumbai, India

Correspondence

R. Mohanan, Department of Biochemistry, St. Thomas College, Palai, Kottayam 686574, India.

Funding information

Glowderma Pvt Ltd

\begin{abstract}
The prevalence of liver disease is increasing year by year and it is recognized as a main health burden across the world. Nowadays, dietary nutraceuticals are found to be very effective in the prevention and treatment of liver diseases. The virgin coconut oil and phosphatidylcholine are found to have a wide range of therapeutic efficacy and the most important among them is its hepatoprotective activity. In the present study, we had evaluated the hepatoprotective effect of the novel formulation with the combination of these two which is named as Phoscoliv. For the study, adult Wistar rats were grouped into Normal control, Paracetamol-treated, and Paracetamol along with Phoscoliv-treated group. In order to evaluate the hepatoprotective effect of the drug, various parameters were analyzed. Data obtained from the study showed that Phoscoliv supplementation were found to significantly boost up the antioxidant status by enhancing the SOD, CAT, GPx, and GSH level and thereby inhibit the generation of ROS and also blocked lipid peroxidation, which was confirmed by the reduced level of TBARS. The release of pro-inflammatory cytokines was also decreased, which was eventually helped to maintain the normal architecture of the liver. Thus, from the overall result of this study reveals that Phoscoliv can be effectively used as a potent and safe hepatoprotective medicine.
\end{abstract}

\section{Practical applications}

The over or unwanted usage of synthetic medicine is a serious problem because it can cause so many adverse health effects. Liver-related disorders are the major side effects of these drugs. Food habits of ancient people dictate that there is no other better medicine than a good food. So, treating a disease with a food or compounds derived from a food item will be more effective. Virgin coconut oil is a type of natural and organic oil, which has the capability of maintaining the body in a healthy state. Likewise, phosphatidylcholines are very important phospholipid nutrients necessary to keep the cells healthy. Both these have the potential to protect and prevent the liver damages. Therefore, the combination of these two can exhibit profound hepatoprotective activity.

KEYWORDS

antioxidants, cytokines, hepatotoxicity, lipid peroxidation, paracetamol, Phoscoliv 


\section{1 | INTRODUCTION}

Virgin coconut oil is a naturally processed oil, obtained either from coconut kernel or coconut milk, which is one of the important sources of dietary fat. It is processed using a low heat process and its nutritional value and health benefits have been recognized for many years. So, it has a significant role in our diet (Kamariah et al., 2008). There are lots of scientific reports supporting the pharmaceutical properties of virgin coconut oil as compared to other oils. This includes its hepatoprotective, anti-inflammatory, antimicrobial, anti-hypercholesterol effect, and moreover, it helps to improve the antioxidant status and control the lipid peroxidation process (German \& Dillard, 2004; Nevin \& Rajamohan, 2004; Van Immerseel et al., 2004). Therefore, virgin coconut oil gains more acceptance because of its nutraceutical and pharmaceutical properties.

All the beneficial or detrimental effects resulting from the consumption of food, drinks, or drugs will ultimately reflect in the cells and cellular activities. So, maintaining the cells in a healthier condition is very crucial to get rid of many kinds of diseases. Phosphatidylcholine is a phospholipid which is considered as one of the major building blocks and essential nutrient for the cells (Vance \& Ridgway, 1988). It gains utmost importance among the researchers as it possesses various properties like antioxidant, anti-inflammatory, hepatoprotection, anti-fibrotic etc. (Akin et al., 2007; Chung et al., 2014). There are lots of previous studies showing the beneficial effects and hepatoprotective activity of phospholipids isolated from various plants and animals (Bubnova \& Aronov, 2014; Hassanein et al., 2011; Li et al., 2018; Yang, 2017).

The hepatoprotective properties of phosphatidylcholine are mainly based on the membrane-dependent activities, specifically, maintaining the cellular integrity, regeneration, and protection of the damaged cells, controlling the metabolic processes that take place in between the intracellular and intercellular region by being involved in the passage of different molecules through the membranes (especially in the hepatocytes), stimulating the activation of membrane bound proteins like lecithin cholesterol acyltransferase, lipoprotein lipase, cytochrome oxidase etc., and possessing bounded polyunsaturated fatty acids which are the precursors of certain cytoprotectants such as eicosanoids which will be released as required (Gundermann, 1993; Kuntz, 1995). The ability of phosphatidylcholine to dissolve the fats accumulated in the liver will be very effective for the people having fatty liver (Fricker, 2010; Zeisel et al., 1991). Therefore, it is inevitable but the endogenous production of phosphatidylcholine is not enough to meet the normal bodily activities. So, it is very necessary to include it in our regular diet, the deficiency can adversely affect the normal functioning of liver.

The liver is one of the most important organs which plays a significant role in maintaining the homeostasis of the body by performing the functions like metabolism, secretion, storage, and detoxification (Maheswari et al., 2008). As a part of the detoxification process, the liver is continually exposed to various xenobiotics, chemotherapeutic agents, or other pollutants from the environment. Therefore, the liver is more susceptible to toxic hepatic injuries and infections. In recent years, hepatic diseases are becoming a global issue and the number of patients are also increasing (Francesca, 2012). The major contributing factor of hepatotoxicity is either due to the adverse side effect caused by the use of conventional drugs or the overdose of certain analgesic drugs like paracetamol, which is commonly known as drug-induced hepatotoxicity (Arhoghro et al., 2009; Tanne, 2006).

Paracetamol (PCM) or acetaminophen is a very commonly used analgesic or antipyretic drug (Cover \& Mansouni, 2005). In the therapeutic dosage of PCM, it will rapidly metabolize in the liver and majority is eliminated by conjugation to nontoxic sulfated and glucuronidated metabolites and a small percentage of PCM will undergo oxidation with the help of cytochrome $p-450$ enzyme resulting in the formation of highly reactive $\mathrm{N}$-acetyl-p-benzoquinonimine (NAPQI) (Bunchorntavakul \& Reddy, 2013; McGill \& Jaeschke, 2013). In the normal process of detoxification, this reactive NAPQI is detoxified by the antioxidant enzyme glutathione (GSH) and always maintains an equilibrium to neutralize the toxic environment (Song et al., 2014). However, overdose can lead to the excessive production of NAPQI that can inflict a shift in this equilibrium due to the saturation of sulfation and glucuronidation process and depletion of GSH, which leads to create an oxidative stress condition (Dai et al., 2006). As a result, progressively more reactive oxygen species (ROS) will be released and that will trigger the cellular necrosis by organelle swelling along with membrane dysfunction through disruption of the mitochondrial membrane permeability transition pores (Yuan \& Kaplowitz, 2013).

In addition to this, drug-induced hepatotoxicity is often allied with an inflammatory response which will significantly intensify the severity of liver injury (Rolando et al., 2000). Impairment in the liver function has harmful effects on the other organs too because of the toxic factors released from damaged liver and also due to the loss of detoxifying pathways (Ferenci, 2002). Therefore, by considering the lack of reliability of modern medicines and the rigorousness of the liver diseases, the exploration of a novel and potent formulation is very essential. Moreover, the efficacy and safety of naturally derived food products are starting to get the attention of an increasing number of researchers and pharmaceuticals (Xie, 2016).

Thus, the aim of the present study was to evaluate the hepatoprotective effect of Phospholipid-virgin coconut oil combination (hereinafter referred to as "Phoscoliv," patent pending and registered formulation) on PCM-induced liver toxicity. So, we assume that the combination of phospholipids and Virgin coconut oil act synergistically and bring out a strong hepatoprotective effect.

\section{MATERIALS AND METHODS}

\section{$2.1 \mid$ Chemicals}

All the chemicals used for the study were high quality analytical grade reagents. SGOT, SGPT, and ALP kits were obtained from M/S Agappe diagnostics Company India Pvt Ltd. and ELISA Kits were purchased from sigma-Aldrich, USA. 


\section{2 | Preparation of Phoscoliv}

Phoscoliv is a novel formulation which consists of phosphatidylcholine and virgin coconut oil. Virgin coconut oil is prepared from the solid endosperm of mature coconut. It was crushed and made into a viscous slurry. The slurry was then squeezed through cheese cloth to obtain coconut milk and it was refrigerated for $48 \mathrm{hr}$. After $48 \mathrm{hr}$, the milk was subjected to mild heating $\left(50^{\circ} \mathrm{C}\right)$ in a thermostat oven. The obtained virgin coconut oil was filtered through cheese cloth (Nevin \& Rajamohan, 2006).

For the preparation of Phoscoliv, different ratios of phosphatidylcholine and virgin coconut oil were selected. Each composition with different ratios were mixed thoroughly for $3 \mathrm{hr}$ using a shaker and then, it was filtered through cheese cloth. Again the mixing process was repeated for $1 \mathrm{hr}$ and strained out. From the screening study, it was found that, phosphatidylcholine and virgin coconut oil in the ratio 40: 60 showed potent hepatoprotective effect by evaluating the liver marker enzymes (Data not shown). Hence, this ratio was used for the present study.

\section{3 | Animals}

Healthy adult male Wistar rats (weighing 150-200 g) bred in the host department animal facility were used for this study. They were kept under a controlled environment, temperature $\left(24^{\circ} \mathrm{C}-26^{\circ} \mathrm{C}\right)$, humidity (55\%-60\%), and photoperiod (12:12 hr light-dark cycle). The rats were housed in the cages containing sterile paddy husk as bedding material throughout the experiment and the commercial laboratory balanced diet (Amrut laboratory Animal feeds, Maharashtra, India) and tap water were provided ad libitum. The animals received humane care, in compliance with the host institutional animal ethics guidelines. All experiments were conducted as per the guidelines of the animal ethics committee CPCSEA (Registration No. CAF/361/2015) according to Government of India accepted principles for laboratory animals' use and care.

\subsection{Study design and experimental protocol}

For the study rats were divided into three groups and each group contain six rats.

Group I served as Normal control rats (N)

Group II served as Paracetamol-treated rats (PCM) $(750 \mathrm{mg} / \mathrm{Kg}$ b.wt.)

Group III served as Phoscoliv-treated group (PCM+PL) $(0.5$ $\mathrm{ml} / 100 \mathrm{~g}$ b.wt.)

Each day Group II and III received a single dose of $750 \mathrm{mg} / \mathrm{Kg}$ b.wt. Paracetamol (Uchendu et al., 2018) and Group III alone received a single dose of $0.5 \mathrm{ml} / 100 \mathrm{~g}$ b.wt. Phoscoliv, administered through intragastrically [Dose was selected from preliminary screening study (Data not shown)].

At the end of 30 days of experiment, blood sample of each rat was collected from retro orbital plexus into a sterile tube for separating serum for the estimation of biochemical parameters. Rats were then sacrificed by euthanasia and liver tissue was dissected out. For histological analysis, a portion of the liver tissue was transferred into $10 \%$ buffered formalin and another portion was used for the preparation of tissue homogenate.

\subsection{1 | Estimation of antioxidant activity}

Assay for the estimation of catalase (CAT) activity was determined using the method of Maehly and Chance (1954). The activity of glutathione peroxidase (GPx) was determined by the method of Lawrence and Burk (1976) as modified by Agergaard and Jensen (1982). Superoxide dismutase (SOD) activity was determined using the method described by Kakkar et al. (1984). The enzyme activity was evaluated in liver tissue homogenate and its activity is expressed in unit/mg proteins.

\subsubsection{Estimation of glutathione content (GSH)}

In liver homogenate GSH content was estimated according to the method of Benke and Murphy (1974).

\subsubsection{Estimation of malondialdehyde (MDA)}

Liver tissue was homogenized in phosphate buffer (0.12M) pH 7.5, centrifuged, and the supernatant was used for the estimation of MDA by the method of Ohkawa (1979).

\subsubsection{Estimation of SGOT, SGPT, and ALP}

The serum levels of Serum glutamic pyruvic transaminase (SGPT), Serum glutamic oxaloacetic transaminase (SGOT), and Alkaline phosphatase (ALP) were measured using the diagnostic kits from M/S Agappe diagnostics Company, India.

\subsection{5 | Estimation of pro-inflammatory cytokines}

The serum level of cytokines was determined by enzyme-linked immunosorbent assays (ELISA). IL- 6 and TNF- $\alpha$ were measured by following the instruction of manufactures (Sigma-Aldrich, USA).

\subsubsection{Histopathological analysis of liver tissue}

The entire liver tissue was rapidly dissected out and tissue sections $(5 \mu \mathrm{m})$ fixed by immersion at room temperature in $10 \%$ formalin solution. For the histological examinations, paraffin-embedded tissue sections of liver tissue were stained with hematoxylin-eosin (H\&E). The tissue samples were then examined and photographed under a light 
microscope for observation of structural abnormality. The severity of liver tissue inflammation was judged by two-independent observers blinded to the experimental protocol. The degree and severity of hepatocellular changes were scored based on the grading system done by El-Beshbishy et al. (2010). The severity of various features of hepatic injury was evaluated based on those following scoring schemes: (-) Normal, (+) Mild effect, (++) Moderate effect, and (+++) Severe effect.

\subsection{7 | Assay of protein}

Protein in liver homogenate was assayed by the method of Lowry et al. (1951).

\subsection{8 | Statistical analysis}

The results were analyzed using a statistical program SPSS/PC+, version 11.0 (SPSS Inc., Chicago, IL, USA). One-way ANOVA was employed for comparison test of significant differences among groups were determined. Pair-fed comparisons between the groups were made by Duncan's multiple range tests. $p<.05$ was considered significant.

\section{3 | RESULTS}

\subsection{Effect of PL on antioxidant enzymes activity}

The protective effect of PL against the severe oxidative stress induced by PCM was measured by evaluating the activity of the antioxidant enzymes. SOD, CAT, and GPx are the major free radical scavengers which were reduced significantly in PCM-treated rats as compared to the normal control rats. This indicates that there was an excessive amount of ROS generation by PCM administration. In contrast, treatment of rats with PL significantly $(p<.05)$ increased the activity of SOD, CAT, and GPx as similar to normal control group. Result is shown in the Figure 1.

\subsection{Effect of PL on hepatocellular antioxidant enzyme GSH}

The GSH activity was depleted significantly $(p<.05)$ in the liver tissue of PCM-treated rats as compared to the control group. However, the treatment with PL showed maximum restoration of GSH and enhance the GSH status in the body (Figure 2).

\subsection{Effect of PL on the levels of SGOT, SGPT, and ALP}

The serum SGPT, SGOT, and ALP in the rats treated with PCM was found to be significantly elevated $(p<.05)$ and it was the indication of severe liver necrosis. However, it was noticed that the level of

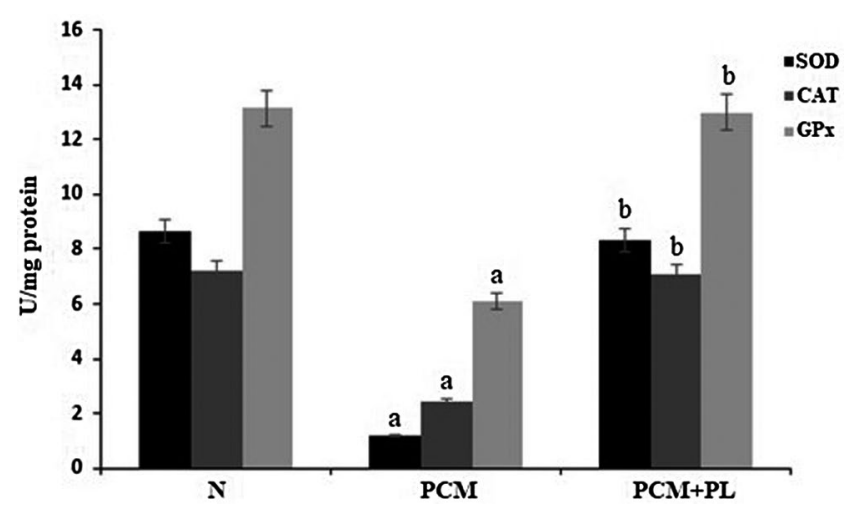

FIGURE 1 Effect of PL on the enzymatic antioxidant activities of SOD, CAT, and GPx enzymes. The values expressed as average of six samples \pm SD in each group. "a"-Statistical difference with normal group at $p \leq .05$. " $b$ "-Statistical difference with PCM-treated rats at $p \leq .05$. Catalase, $\mathrm{U}-\mu \mathrm{mol} \mathrm{H}_{2} \mathrm{O}_{2}$ decomposed/min; GPx, $\mathrm{U}$ - $\mathrm{mmol}$ NADPH oxidized/min; SOD, U-enzyme concentration required to inhibit chromogen production by $50 \%$ in $1 \mathrm{~min}$

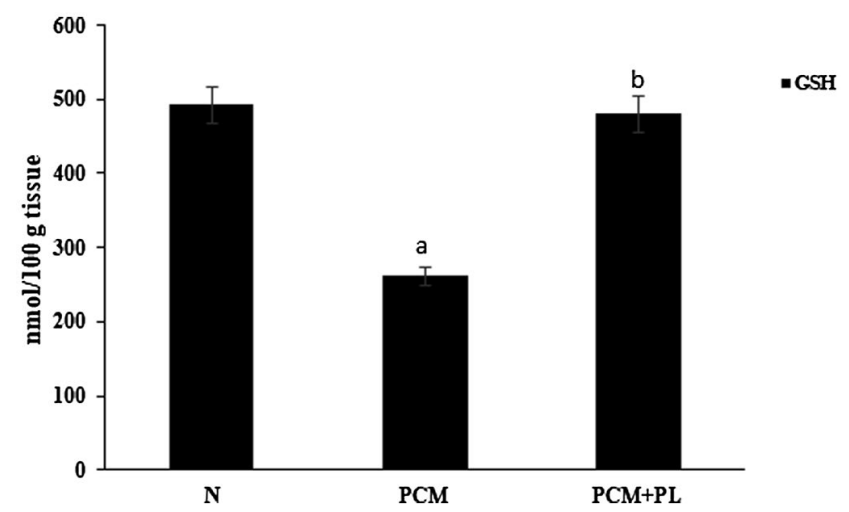

FIGURE 2 Effect of PL on GSH level. Values expressed as average of six samples \pm SD in each group. "a"-Statistical difference with normal group at $p \leq .05$. "b"-Statistical difference with PCMtreated rats at $p \leq .05$.

these liver marker enzymes was maintained almost closer to normal by the administration of PL. Hence, it clearly showed the protective effect of PL over the liver enzyme leakage due to the PCM induction. Results are shown in the Figure 3.

\subsection{Effect of PL on lipid peroxidation end product TBARS}

The result shows that the administration of PCM leads to an increased generation of free radicals thus, immense lipid peroxidation process was taking place. As a result, the level of TBARS was significantly increased which led to the deterioration of hepatocyte as compared to the normal control. In contrast, the group treated with PCM along with PL significantly $(p<.05)$ reduced the TBARS level (Figure 4). 


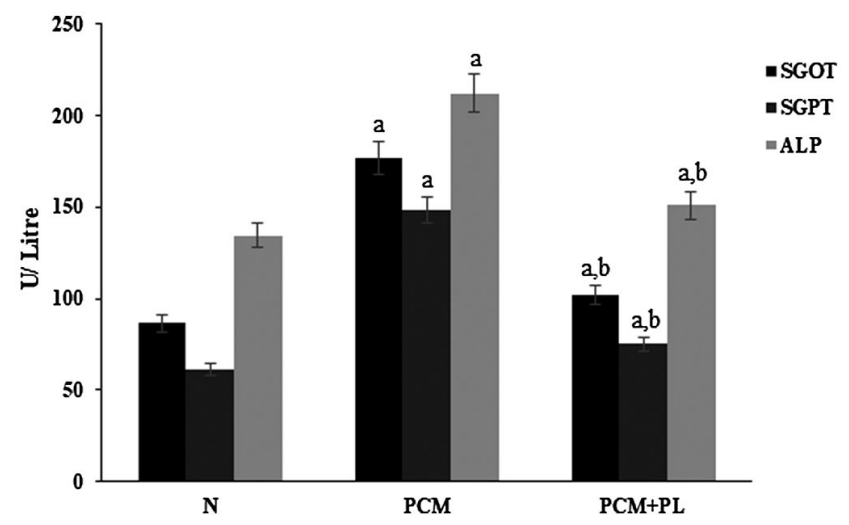

FIGURE 3 Effect of PL on liver enzyme markers. The values are expressed as mean \pm SD of six rats in each group. a-Statistical difference with control group at $p<.05$. b-Statistical difference with PCM-treated rats at $p<.05$. U: SGOT- $\mu$ mol of oxaloacetate liberated $/ \mathrm{min} / \mathrm{mg}$ protein; SGPT- $\mu \mathrm{mol}$ of pyruvate formed $/ \mathrm{min} / \mathrm{mg}$ protein; ALP-amount of enzyme to decompose $1 \mu$ mole of P-NPP/ minute at $25^{\circ} \mathrm{C}$

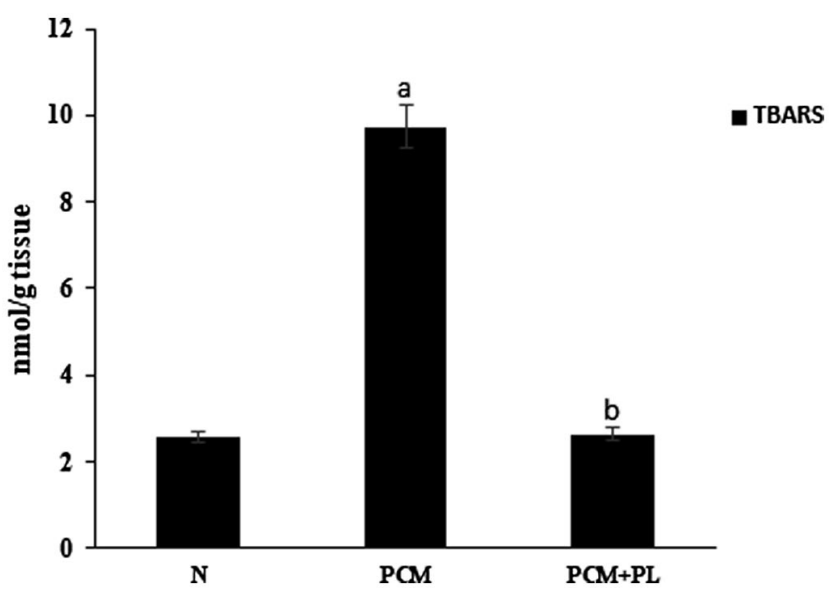

FIGURE 4 Effect of PL on TBARS level. Values expressed as average of six samples \pm SD in each group. "a"-Statistical difference with normal group at $p \leq .05$. "b"-Statistical difference with PCMtreated rats at $p \leq .05$

\section{5 | Effect of PL on cytokines like IL-6 and TNF- $\alpha$}

Inflammatory condition developed as a result of hepatic toxic injury was studied by measuring the pro-inflammatory cytokines like IL- 6 and TNF- $\alpha$. They are released into the bloodstream both from the liver and other distal sites. The results also indicated that PCMtreated control group showed elevated levels of IL- 6 and TNF- $\alpha$ in comparison to the normal control. However, when comparing PL with PCM control, the release of excess pro-inflammatory cytokines was significantly $(p<.05)$ blocked (Figure 5$)$.

\subsection{Histopathological examination of liver tissue}

Table 1 shows the histological scoring of liver tissue. From the stained section of liver tissue shows that the normal control group had

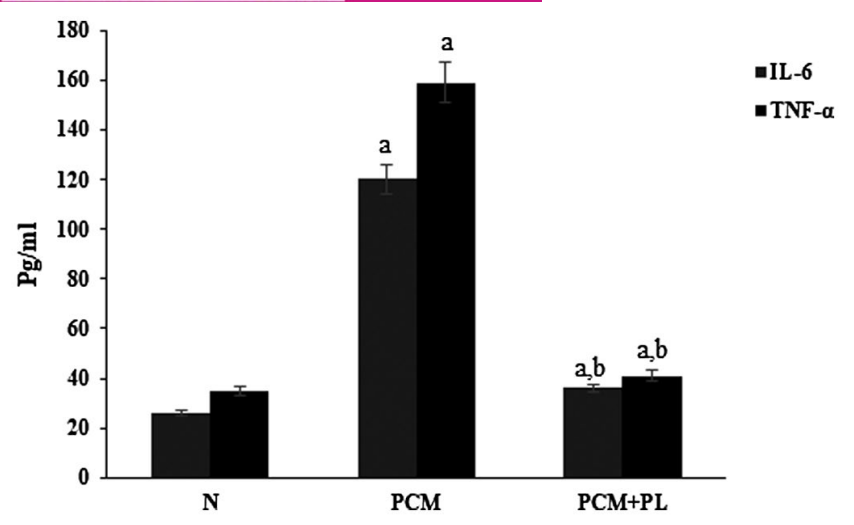

FIGURE 5 Effect of PL on pro-inflammatory cytokines. Values expressed as average of six samples \pm SD in each group. "a"Statistical difference with normal group at $p \leq .05$. "b"-Statistical difference with PCM-treated rats at $p \leq .05$

well-defined structure and arrangements of hepatic cells whereas, PCM-treated group showed degenerative changes characterized by loss of tissue architecture with cells showing granular cytoplasm and section also shows inflammatory cell infiltrates and liver steatosis. The rats treated with $\mathrm{PL}$ showed its effect on liver protection against the drug. PL maintained the tissue architecture almost similar to the normal liver tissue and protected from steatosis and severe infiltration of inflammatory cells (Figure 6).

\section{4 | DISCUSSION}

Drug-induced hepatotoxicity is one of the major reasons for the mortality and morbidity of human beings across the world (Bhawna \& Kumar, 2009). The common xenobiotic-induced experimental model used for the screening of the hepatoprotective effect of various drugs is PCM-induced liver injury (Boyd \& Bereczky, 1966). At higher doses, $\mathrm{PCM}$ causes hepatic necrosis by increasing the amount of reactive NAPQI and this will bind to the biomolecules and attack them (Ramachandra et al., 2007). PCM is also directly involved in the induction of oxidative stress resulting in lipid peroxidation, depletion in antioxidants, and ATP synthesis, and ultimately leading to liver damage (Rabiul et al., 2011).

In order to prevent the cellular damage due to the excessive production of NAPQI, the well-known antioxidant GSH plays a key role. It will act against NAPQI and as a part of it GSH will be oxidized to GSSG (GSH disulfide). Consequently, the level of GSH in the liver will steadily go down, which results in severe oxidative stress (Kerksick \& Willoughby, 2005; Yanpallewar et al., 2003). It has been shown that to keep up the GSH from being depleted, it is very important to provide direct protection against PCM-induced hepatotoxicity (Ahmed \& Khater, 2001). Our study also reveals the same, that is, PCM treatment reduced the GSH level significantly in the liver tissue, but the supplementation of PL strongly helps to enhance the GSH level. 


\begin{tabular}{lllll} 
Treatments & Doses & Steatosis & Necrosis & Inflammation \\
$\mathrm{N}$ & - & - & - & - \\
$\mathrm{PCM}$ & $750 \mathrm{mg} / \mathrm{Kg}$ b.wt. & ++ & +++ & +++ \\
$\mathrm{PCM}+\mathrm{PL}$ & $0.5 \mathrm{~mL} / 100 \mathrm{~g}$ b.wt. & - & - & + \\
\hline
\end{tabular}

TAB LE 1 Histological scoring of liver tissue

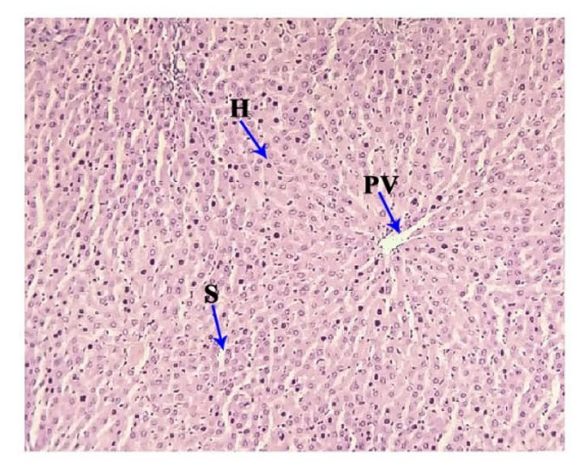

$\mathbf{N}$

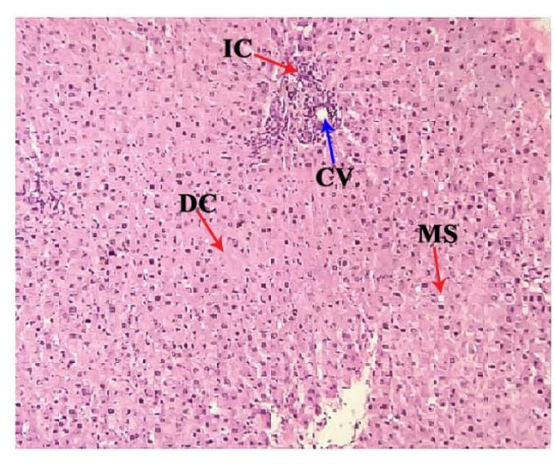

PCM

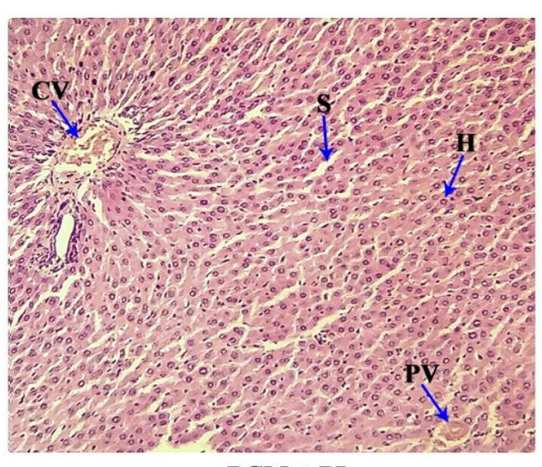

$\mathbf{P C M}+\mathbf{P L}$

FIGURE 6 Histopathological examination of liver tissue (H\&E stain) (40X). Abbreviations: CV, central vein; DC, degenerated cells; H, hepatocytes; IC, inflammatory cells; MS, microsteatosis; PV, portal vein; S, sinusoids

PCM not only depleted the GSH antioxidant, but also affect the other antioxidants in the body. The same condition of GSH was also observed in the case of enzymatic antioxidants like SOD, CAT, and GPx. These are the antioxidants which play a significant role as the natural scavenger system and help to prevent the body, mainly from the superoxide and hydrogen peroxide radicals and act as a shield for cellular components against oxidative stress (Scott et al., 1991). During the induction of PCM there will be an imbalance between ROS generation and antioxidant defense, which will result in stress and cellular damage (Gini \& Muraleedhara, 2010). In this study, it was observed that there was a significant increase in the activities of SOD, CAT, and GPx in PL-treated rats. This showed that PL can reduce the oxidative damage to the tissues besides improving the activity of hepatic antioxidant enzymes. Hence it is due to the ability of PL to interact with hydroxyl, superoxide, alkoxyl, and peroxyl radicals that is able to scavenge them. This indicates that $\mathrm{PL}$ has the potential to protect the liver from oxidative stress induced by drug-mediated liver toxicity.

Studies have shown that the reduction in antioxidant status is also associated with the elevated level of TBARS produced as a result of lipid peroxidation (LPO) (Shao, 2008). It is a kind of destructive process by which polyunsaturated fatty acids in cellular membranes undergo reaction with oxygen, resulting in the formation MDA and other compounds (Muriel et al., 1992). LPO disturbs the membrane potential, which will lead to tissue necrosis. It was clearly observed that there was a significant increase in TBARS level in liver tissue intoxicated with PCM and reduced by the administration of PL. This shows that due to its strong antioxidant action, LPO is inhibited and maintain the membranes from free radical attack.

All the changes inflicted by PCM finally end in toxic injuries that become the causative factor for the activation of Kupffer cells and adjacent sinusoidal endothelial cells to secrete different mediators, including pro-inflammatory cytokines like TNF $\alpha$, IL6 along with ROS (Laskin \& Laskin, 2001). These pro-inflammatory cytokines can induce apoptosis and impairment in cellular function by amplifying the inflammatory processes and induce damage to the hepatocytes and other hepatic cells which further creates a chronic inflammatory condition (Lacour et al., 2005). In our study, we also noticed that these pro-inflammatory cytokines in PCM-treated rats were very high, but PL interrupts the release of cytokines and protect the hepatocytes from inflammatory mediators. 
Liver damage was confirmed by estimating the levels of SGOT, SGPT, and ALP. These are the liver enzyme markers which are commonly used to diagnose liver injuries. By the excessive intake of drugs like PCM, these enzymes will increase significantly due to the hepatocellular injury and as a result, the enzymes will leak into the bloodstream and their concentration will be hiked (Nkosi et al., 2005). Elevated levels of liver marker enzymes were found that PCM-treated rats due to the extensive liver damage induced by the drug. We found that PL administration reduced the concentrations of SGOT, SGPT, and ALP levels. Therefore, it is clear that PL helps to prevent the leakage of marker enzymes by protecting the liver tissues and cellular constituents normally.

The liver is constantly metabolizing drugs and other xenobiotics, so it is very much prone to drug-induced damages. The ultimate effect of all the toxic mechanism can be seen in the histological study of liver tissue. The hepatoprotective effect of any substance is mainly dependent on its ability to restore the normal histology of liver or to reduce the toxic effects induced by the external factors. In the present study, liver section treated with PCM displayed the severity and intensity of the over dosage of such kind of drugs over the normal architecture of liver. It may be due to the overproduction of reactive free radicals which mediate the tissue damage. Along with the negative side effects of PCM intoxication, we found the competency of PL to protect the liver from drug-induced toxicity. PL helps to boost up the survival and regeneration of hepatocytes and maintain the liver cells in their normal state without leading to the different stages of liver damage. Thus, the hepatoprotective effect of $\mathrm{PL}$ against drug-induced liver toxicity was clearly visible in the histopathological assessment.

\section{5 | CONCLUSION}

The results obtained from the present study shows that, Phoscoliv, the combination of phosphatidylcholine and virgin coconut oil prevented the drug-induced hepatotoxicity via free radical scavenging, reducing inflammation as well as cellular leakage and thereby reverted back to the normal liver morphology. So, Phoscoliv will be a better solution to the people who are suffering from hepatic damage.

\section{ACKNOWLEDGMENT}

We are expressing our sincere gratitude to Mr. Rajesh Khatri, Managing Director of Glowderma Pvt. Ltd., Mumbai for his valuable suggestion and enthusiastic support.

\section{CONFLICT OF INTEREST}

All the authors are disclosing the conflict of interest. Phoscoliv is a patent pending registered product of Glowderma Pvt. Ltd. Mumbai.

\section{AUTHOR CONTRIBUTION}

Sheethal Sreevallabhan: Data curation; Formal analysis; Writingoriginal draft. Ratheesh Mohanan: Conceptualization; Methodology;
Supervision; Writing-review \& editing. Svenia P Jose: Investigation; Software; Validation. Sandya Sukumaran: Methodology; Project administration; Writing-review \& editing. Tariq Jagmag: Funding acquisition; Writing-review \& editing. Jayesh Tilwani: Resources; Visualization. Anuradha Kulkarni: Writing-review \& editing.

\section{DATA AVAILABILITY STATEMENT}

The data that support the findings of this study are available from the corresponding author upon reasonable request.

\section{ORCID}

Ratheesh Mohanan (iD https://orcid.org/0000-0002-4638-1633

\section{REFERENCES}

Agergaard, N., \& Jensen, P. T. (1982). Procedure for blood glutathione peroxidase determination in cattle and swine. Acta Veterinaria Scandinavica, 23(4), 515-527.

Ahmed, M. B., \& Khater, M. R. (2001). Evaluation of the protective potential of Ambrosia maritime extract on acetaminophen-induced liver damage. Journal of Ethnopharmacology, 75(2-3), 169-174. https://doi. org/10.1016/S0378-8741(00)00400-1

Akin, M., Demirbilek, S., Ay, S., Gurunluoglu, K., Turkmen, E., Tas, E., Aksoy, R. T., Baykarabulut, A., \& Edali, M. N. (2007). Attenuation of ureteral obstruction-induced renal injury by polyenylphosphatidylcholine. International Journal of Urology., 14(4), 350-356. https://doi. org/10.1111/j.1442-2042.2006.01717.x

Arhoghro, E. M., Ekpo, K. E., Anosike, E. O., \& Tbeh, G. O. (2009). Effect of aqueous extract of bitter leaf (Vernonia Amygdalina Del) on carbon tetrachloride $(\mathrm{CCl} 4)$ induced liver damage in albino wistar rats. European Journal of Scientific Research, 26(1), 122-130.

Benke, G. M., \& Murphy, S. D. (1974). Effect of TOTP pretreatment on paraoxon and methyl paraoxon detoxification in rats. Research Communications in Chemical Pathology and Pharmacology, 8, 665-672.

Bhawna, S., \& Kumar, S. U. (2009). Hepatoprotective activity of some indigenous plants. International Journal of Pharmtech Research, 1(4), 1330-1334.

Boyd, E. H., \& Bereczky, G. M. (1966). Liver necrosis from paracetamol. British Journal of Pharmacology, 26(3), 606-614. https://doi. org/10.1111/j.1476-538.1966.tb01841.x

Bubnova, M., \& Aronov, D. (2014). The hypolipidemic and hepatoprotective efficacies of an essential phospholipids with methionine and atorvastatin in patients with cardiovascular diseases and diabetes mellitus. Atherosclerosis, 235(2), Article e252. https://doi. org/10.1016/j.atherosclerosis.2014.05.754

Bunchorntavakul, C., \& Reddy, R. (2013). Acetaminophen-related hepatotoxicity. Clinics in Liver Disease, 17(4), 587-607. https://doi. org/10.1016/j.cld.2013.07.005

Chung, S. J., Lee, C. H., Lee, H. S., Kim, S. T., Sohn, U. D., Park, E. S., Bang, J. S., Lee, J. H., Chung, Y. H., \& Jeong, J. H. (2014). The role of phosphatidylcholine and deoxycholic acid ininflammation. Life Science., 108(2), 88-93. https://doi.org/10.1016/j.lfs.2014.05.013

Cover, C., \& Mansouni, A. (2005). Peroxinitrite induced mitochondrial and endonuclease mediated nuclear DNA damage in acetaminophen hepatotoxicity. Journal of Pharmacology and Experimental Therapeutics, 315(2), 879-887. https://doi.org/10.1124/ jpet.105.088898

Dai, G., He, L., Chou, N., \& Wan, Y. J. (2006). Acetaminophen metabolism does not contribute to gender difference in its hepatotoxicity in mouse. Toxicological Sciences, 92(1), 33-41. https://doi.org/10.1093/ toxsci/kfj192

El-Beshbishy, H. A., Mohamadin, A. M., Nagy, A. A., \& Abdel-Naim, A. B. (2010). Amelioration of tamoxifen-induced liver injury in rats by 
grape seed extract, black seed extract and curcumin. Indian Journal of Experimental Biology, 48(3), 280-288.

Ferenci, P., Lockwood, A., Mullen, K., Tarter, R., Weissenborn, K., \& Blei, A. T. (2002). Hepatic encephalopathy-definition, nomenclature, diagnosis, and quantification: final report of the working party at the 11th World Congresses of Gastroenterology, Vienna, 1998. Hepatology, 35(3), 716-721. https://doi.org/10.1053/ jhep. 2002.31250

Francesca, C. (2012). Liver diseases in developing countries. World Journal of Hepatology, 4(3), 66-67. https://doi.org/10.4254/wjh. v4.i3.66

Fricker, G., Kromp, T., Wendel, A., Blume, A., Zirkel, J., Rebmann, H., Setzer, C., Quinkert, R.-O., Martin, F., \& Müller-Goymann, C. (2010). Phospholipids and lipid-based formulations in oral drug delivery. Pharmaceutical Research, 27(8), 1469-1486. https://doi.org/10.1007/ s11095-010-0130-x

German, J. B., \& Dillard, C. J. (2004). Saturated fats: what dietary intake? American Journal of Clinical Nutrition, 80(3), 550-559. https://doi. org/10.1093/ajcn/80.3.550

Gini, K. C., \& Muraleedhara, K. G. (2010). Hepatoprotective effect of Spirulina lonar on paracetamol induced liver damage in rats. Asian Journal of Experimental Biological Sciences, 1(3), 614-623.

Gundermann, K. J. (1993). The essential phospholipids as a membrane therapeutic. Jota Press.

Hassanein, H. D., Naglaa, M. N., Abdelaaty, A. S., Nermin, A. E., Elsayed, A. H. A., Mahmoud, A. S., \& Faiza, M. H. (2011). In-vitro hepatoprotection study, cytotoxicity assay and chromatographic investigation of phospholipids fraction isolated from Cyperus esculentus tubers growing in Egypt. Australian Journal of Basic and Applied Sciences, 5(10), 335-341.

Kakkar, P., Das, B., \& Viswanathan, P. (1984). A modified spectrophotometric assay of superoxide dismutase. Indian Journal of Biochemistry and Biophysics, 21(2), 130-132.

Kamariah, L., Azmi, A., Rosmawati, A., Wai Ching, M. G., Azlina, M. D., Sivapragasam, P., \& Lai, O. M. (2008). Physico-chemical and quality characteristics of virgin coconut oil - a Malaysian survey. Journal of Tropical Agriculture and Food Science, 36(2), 239-248.

Kerksick, C., \& Willoughby, D. (2005). The antioxidant role of glutathione and $\mathrm{N}$-acetyl-cysteine supplements and exercise induced oxidative stress. Journal of the International Society of Sports Nutrition, 2(2), 3844. https://doi.org/10.1186/1550-2783-2-2-38

Kuntz, E. (1995). The "essential" phospholipids in hepatology-Experimental and clinical experiences. Progress in Hepato-Pharmacology, 1, 156-167.

Lacour, S., Jean-Charles, G., Marc, P., \& Ruth, R. (2005). Cytokines as potential biomarkers of liver toxicity. Cancer Biomarker, 1(1), 29-39. https://doi.org/10.3233/CBM-2005-1105

Laskin, D. L., \& Laskin, J. D. (2001). Role of macrophages and inflammatory mediators in chemically induced toxicity. Toxicology, 160(1-3), 111-118. https://doi.org/10.1016/s0300-483x(00)00437-6

Lawrence, R. A., \& Burk, R. F. (1976). Glutathione peroxidase activity in selenium-deficient rat liver. Biochemical and Biophysical Research Communications, 71(4), 952-958. https://doi.org/10.1016/0006291x(76)90747-6

Li, X., He, Q., Hou, H., Zhang, S., Zhang, X., Zhang, Y., Wang, X., Han, L., \& Liu, K. (2018). Targeted lipidomics profiling of marine phospholipids from different resources by UPLC-Q-Exactive Orbitrap/MS approach. Journal of Chromatography B, 1096, 107-112. https://doi. org/10.1016/j.jchromb.2018.08.018

Lowry, O. H., Rosebrough, N. J., Farr, A. L., \& Randall, R. J. (1951). Protein measurement with the Folin phenol reagent. Journal of Biological Chemistry, 193(1), 265-275.

Maehly, A. C., \& Chance, B. (1954). The assay of catalases and peroxidases. Methods of Biochemical Analysis, 1, 357-424. https://doi. org/10.1002/9780470110171.ch14
Maheswari, C., Maryammal, R., \& Venkatanarayanan, R. (2008). Hepatoprotective activity of Orthosiphon stamineus on liver damage caused by paracetamol in rats. Jordan Journal of Biological Sciences, 1(3), 105-108.

McGill, M., \& Jaeschke, H. (2013). Metabolism and disposition of acetaminophen: recent advances in relation to hepatotoxicity and diagnosis. Pharmaceutical Research, 30(9), 2174-2187. https://doi. org/10.1007/s11095-013-1007-6

Muriel, P., Garciapina, T., Perez-Alvarez, V., \& Muelle, M. (1992). Silymarin protect against paracetamol induced lipid peroxidation and liver damage. Journal of Applied Toxicology, 12(6), 439-442.

Nevin, K. G., \& Rajamohan, T. (2004). Beneficial effects of virgin coconut oil on lipid parameters and in vitro LDL oxidation. Clinical Biochemistry, 37(9), 830-835. https://doi.org/10.1016/j.clinbiochem.2004.04.010

Nevin, K. G., \& Rajamohan, T. (2006). Virgin coconut oil supplement diet increases the antioxidant status in rats. Food Chemistry, 99(2), 260266. https://doi.org/10.1016/j.foodchem.2005.06.056

Nkosi, C. Z., Opoku, A. R., \& Terblanche, S. E. (2005). Effect of pumpkin seed (Cucurbitapepo) protein isolate on the activity levels of certain plasma enzymes in $\mathrm{CCl} 4$-induced liver injury in low-protein fed rats. Physical Therapy Research, 19(4), 341-345.

Ohkawa, H., Ohishi, N., \& Yagi, K. (1979). Assay for lipid peroxides in animal tissues by thiobarbituric acid reaction. Analytical Biochemistry, 95(2), 351-358. https://doi.org/10.1016/0003-2697(79)90738-3

Rabiul, H., Subhasish, M., Sinha, S., Roy, M. G., Sinha, D., \& Gupta, S. (2011). Hepatoprotective activity of Clerodendron inerme against paracetamol induced hepatic injury in rats for pharmaceutical product. International Journal of Drug Development and Research, 3(1), 118-126.

Ramachandra Setty, S., Quereshi, A. A., Viswanath Swamy, A., Patil, T., Prakash, T., Prabhu, K., \& Veeran Gouda, A. (2007). Hepatoprotective activity of Calotropis procera flowers against paracetamol-induced hepatic injury in rats. Fitoterapia, 78(7-8), 451-454. https://doi. org/10.1016/j.fitote.2006.11.022

Rolando, N., Wade, J., Davalos, M., Wendon, J., Philpott-Howard, J., \& Williams, R. (2000). The systemic inflammatory response syndrome in acute liver failure. Hepatology, 32(4 Pt 1), 734-739.

Scott, M. D., Lubin, B. H., Zuo, L., \& Kuypers, F. A. (1991). Erythro-cyte defense against hydrogen peroxide: preeminent importance of catalase. Journal of Laboratory and Clinical Medicine, 118(1), 7-16. https:// doi.org/10.5555/uri:pii:002221439190110S

Shao, H.-B., Chu, L.-Y., Lu, Z.-H., \& Kang, C.-M. (2008). Primary antioxidant free radical scavenging and redox signaling pathways in higher plant cells. International Journal of Biological Science, 4(1), 8-14. https://doi.org/10.7150/ijbs.4.8

Song, Z., McClain, C. J., \& Chen, T. (2014). S-adenosylmethionine protects against paracetamol-induced hepatotoxicity. Pharmacology, 71(4), 199-208.

Tanne, J. (2006). Paracetamol causes most liver failure in UK and US. British Medical Journal, 332(7542), 628.

Uchendu, I. K., Agu, C. E., Orji, O. C., Nnedu, E. B., Arinze, C., Uchenna, A. C., \& Okongwu, U. C. (2018). Effect of tomato (Lycopersicon esculentum) extract on acetaminophen-Induced acute hepatotoxicity in Albino Wistar rat. Bioequivalence \& Bioavailability International Journal, 2(1), 000119. https://doi.org/10.23880/BEBA-16000119

Van Immerseel, F., De Buck, J., Boyen, F., Bohez, L., Pasmans, F., Volf, J., \& Ducatelle, R. (2004). Medium-chain fatty acids decrease colonization and invasion through hilA suppression shortly after infection of chickens with Salmonella enterica serovar enteritidis. Applied and Environmental Microbiology, 70(6), 3582-3587. https://doi. org/10.1128/AEM.70.6.3582-3587.2004

Vance, D. E., \& Ridgway, N. D. (1988). The methylation of phosphatidylethanolamine. Progress in Lipid Research, 27(1), 61-79. https://doi. org/10.1016/0163-7827(88)90005-7 
Xie, W., Wang, M., Chen, C., Zhang, X., \& Melzig, M. F. (2016). Hepatoprotective effect of isoquercitrin against acetaminophen-induced liver injury. Life Science, 152, 180-189. https://doi. org/10.1016/j.Ifs.2016.04.002

Yang, F., Ruan, J., Wang, T., Luo, J., Cao, H., Song, Y., Huang, J., \& Hu, G. (2017). Improving effect of dietary soybean phospholipids supplement on hepatic and serum indexes relevant to fatty liver hemorrhagic syndrome in laying hens. Animal Science Journal, 88(11), 1860-1869. https://doi.org/10.1111/asj.12832

Yanpallewar, S. U., Sen, S., Tapas, S., Kumar, M., Raju, S. S., \& Acharya, S. B. (2003). Effect of Azadirachta indica on paracetamol-induced hepatic damage in Albino rats. Phytomedicine, 10(5), 391-396. https:// doi.org/10.1078/0944-7113-00230

Yuan, L., \& Kaplowitz, N. (2013). Mechanisms of drug-induced liver injury. Clinical Liver Disease, 17(4), 507-518. https://doi.org/10.1016/j. cld.2013.07.002
Zeisel, S. H., da Costa, K. A., Franklin, P. D., Alexander, E. A., Lamont, J. T., Sheard, N. F., \& Beiser, A. (1991). Choline, an essential nutrient for humans. Fedarations of American Societies for Experimental Biology, 5(7), 2093-2098.

How to cite this article: Sreevallabhan S, Mohanan R, Jose $\mathrm{SP}$, et al. Hepatoprotective effect of essential phospholipids enriched with virgin coconut oil (Phoscoliv) on paracetamolinduced liver toxicity. J Food Biochem. 2021;00:e13606. https://doi.org/10.1111/jfbc.13606 